OPEN ACCESS

Edited by: Gabriella D'Arcangelo,

Rutgers University, USA

Reviewed by: Nicola Berretta,

Fondazione Santa Lucia, Italy Jack M. Parent,

University of Michigan, USA

*Correspondence:

Carola A. Haas carola.haas@uniklinik-freiburg.de

†These authors have contributed equally to this work.

Received: 31 March 2016 Accepted: 08 July 2016 Published: 28 July 2016

Citation: Orcinha C, Münzner G, Gerlach J, Kilias A, Follo M, Egert U and Haas CA (2016) Seizure-Induced Motility of Differentiated Dentate Granule Cells Is Prevented by the Central Reelin Fragment. Front. Cell. Neurosci. 10:183. doi: $10.3389 /$ fncel.2016.00183

\section{Seizure-Induced Motility of Differentiated Dentate Granule Cells Is Prevented by the Central Reelin Fragment}

\author{
Catarina Orcinha ${ }^{1,2,3,4+}$, Gert Münzner ${ }^{1,2,3+}$, Johannes Gerlach 1,2,3, Antje Kilias ${ }^{3,4,5}$, \\ Marie Follo ${ }^{2,6}$, Ulrich Egert ${ }^{4,5,7}$ and Carola A. Haas ${ }^{1,2,4,7 *}$
}

\begin{abstract}
${ }^{1}$ Experimental Epilepsy Research, Department of Neurosurgery, Medical Center, University of Freiburg, Freiburg, Germany, ${ }^{2}$ Faculty of Medicine, University of Freiburg, Freiburg, Germany, ${ }^{3}$ Faculty of Biology, University of Freiburg, Freiburg, Germany, ${ }^{4}$ Bernstein Center Freiburg, University of Freiburg, Freiburg, Germany, ${ }^{5}$ Laboratory for Biomicrotechnology, Department of Microsystems Engineering, University of Freiburg, Freiburg, Germany, ${ }^{6}$ Lighthouse Core Facility, Department of Medicine I, Medical Center, University of Freiburg, Freiburg, Germany, ${ }^{7}$ BrainLinks-BrainTools, Cluster of Excellence, University of Freiburg, Freiburg, Germany
\end{abstract}

Granule cell dispersion (GCD) represents a pathological widening of the granule cell layer in the dentate gyrus and it is frequently observed in patients with mesial temporal lobe epilepsy (MTLE). Recent studies in human MTLE specimens and in animal epilepsy models have shown that a decreased expression and functional inactivation of the extracellular matrix protein Reelin correlates with GCD formation, but causal evidence is still lacking. Here, we used unilateral kainate (KA) injection into the mouse hippocampus, an established MTLE animal model, to precisely map the loss of reelin mRNA-synthesizing neurons in relation to GCD along the septotemporal axis of the epileptic hippocampus. We show that reelin mRNA-producing neurons are mainly lost in the hilus and that this loss precisely correlates with the occurrence of GCD. To monitor GCD formation in real time, we used organotypic hippocampal slice cultures (OHSCs) prepared from mice which express enhanced green fluorescent protein (eGFP) primarily in differentiated dentate granule cells. Using life cell microscopy we observed that increasing doses of KA resulted in an enhanced motility of eGFP-positive granule cells. Moreover, KA treatment of OHSC resulted in a rapid loss of Reelin-producing interneurons mainly in the hilus, as observed in vivo. A detailed analysis of the migration behavior of individual eGFP-positive granule cells revealed that the majority of these neurons actively migrate toward the hilar region, where Reelin-producing neurons are lost. Treatment with KA and subsequent addition of the recombinant R3-6 Reelin fragment significantly prevented the movement of eGFP-positive granule cells. Together, these findings suggest that GCD formation is indeed triggered by a loss of Reelin in hilar interneurons.

Keywords: temporal lobe epilepsy, hippocampus, granule cell dispersion, migration, kainate, motility 


\section{INTRODUCTION}

Characteristic features of mesial temporal lobe epilepsy (MTLE) are recurrent focal seizures and Ammon's horn sclerosis (AHS) characterized by neuronal loss and granule cell dispersion (GCD), an abnormal broadening of the dentate granule cell layer (GCL; Houser, 1990; Haas et al., 2002). There is recent evidence that a loss of the extracellular matrix protein Reelin is involved in the development of GCD, since the Reelin-deficient reeler mouse (D’Arcangelo et al., 1995; Hirotsune et al., 1995) shows a disorganized GCL, reminiscent of GCD (Frotscher et al., 2003). Moreover, GCD formation has been shown to be accompanied by a loss of Reelin-producing neurons in the hippocampus of MTLE patients (Haas et al., 2002) and in rodent epilepsy models (Heinrich et al., 2006; Gong et al., 2007; Antonucci et al., 2008; Duveau et al., 2011). A local reduction of GCD has been achieved by infusion of recombinant Reelin into the rodent hippocampus during epileptogenesis, pointing to a causal role of Reelin in maintaining lamination in the adult brain (Müller et al., 2009).

Reelin is a key regulator of neuronal positioning during brain development, but Reelin is also important for synaptic function and memory formation in the adult brain (Herz and Chen, 2006; Lane-Donovan et al., 2015). Reelin is synthesized and secreted by Cajal-Retzius (CR) cells and interneurons into the extracellular matrix (Alcántara et al., 1998; Pesold et al., 1998), where fulllength Reelin is proteolytically cleaved into smaller isoforms, an important prerequisite for activation of target cells (Jossin et al., 2004, 2007). The full-length Reelin molecule consists of an N-terminal F-spondin-like sequence, followed by eight Reelin repeats. Cleavage of Reelin can occur at two sites: N-terminal between the second and the third repeat, and C-terminal between the sixth and seventh repeat, generating five possible isoforms depending on the protease in action (Lambert de Rouvroit et al., 1999; Jossin et al., 2004). Specifically, the central region of Reelin (R3-6) has been described to be very important for receptor binding (D'Arcangelo et al., 1999; Jossin et al., 2004; Lee and D’Arcangelo, 2016).

Reelin signaling occurs after binding to lipoprotein receptors, very-low-density lipoprotein receptor (VLDLR) and apolipoprotein E receptor 2 (ApoER2), tyrosine phosphorylation of the intracellular adaptor protein Disabled-1 (Dab1) by Src family kinases, and the subsequent activation of downstream effectors, which target the actin and microtubule cytoskeleton (Tissir and Goffinet, 2003; Stolt and Bock, 2006; Jossin and Goffinet, 2007; Leemhuis and Bock, 2011). Recently, binding of Reelin to Ephrins has been reported, although the physiological functions of these interactions remain poorly understood (Sentürk et al., 2011; Bouché et al., 2013).

Granule cell dispersion can be induced experimentally in adult mice by unilateral injection of kainate (KA), an agonist of the excitatory neurotransmitter glutamate (Bouilleret et al., 1999; Heinrich et al., 2006; Häussler et al., 2012). In this animal model, AHS including neuronal cell loss and GCD develops within 3 weeks after KA injection in spite of the loss of dentate neurogenesis (Kralic et al., 2005; Heinrich et al., 2006; Nitta et al., 2008). In addition, spontaneous, focal epileptic seizures develop similar to human MTLE (Riban et al., 2002; Häussler et al., 2012).
GCD can also be induced in vitro in organotypic hippocampal slice cultures (OHSCs) by KA application (Tinnes et al., 2011, 2013). In this in vitro model, GCD has been shown recently to occur via somal translocation of differentiated granule cells (Murphy and Danzer, 2011; Chai et al., 2014), but so far the molecular mechanism has remained unclear.

In the present study, we show in the intrahippocampal KA mouse model that GCD formation and loss of reelin mRNAproducing neurons are spatially correlated and that this loss mainly affects the hilus. In addition, we present evidence in OHSC that, like in vivo, KA treatment causes a complete loss of Reelin-producing hilar neurons. Moreover, we show in real time by life cell microscopy that differentiated enhanced green fluorescent protein (eGFP)-positive granule cells actively migrate toward the Reelin-free hilar region and that this migration process can be prevented by application of the central R3-6 Reelin fragment.

\section{MATERIALS AND METHODS}

\section{Animals}

Experiments were performed with C57BL/6 and Thy1-eGFP mice (M-line, C57BL/6 background). All animal procedures were carried out in accordance with the guidelines of the European Community's Council Directive of 22 September 2010 (2010/63/EU) and were approved by the regional council (Regierungspräsidium Freiburg).

\section{Intrahippocampal Kainate Injection}

Adult male (7-12 weeks of age) C57BL/6 mice were used for unilateral intrahippocampal KA injections as described previously (Heinrich et al., 2006; Häussler et al., 2012). In brief, anesthetized mice (ketamine hydrochloride $100 \mathrm{mg} / \mathrm{kg}$, xylazine $5 \mathrm{mg} / \mathrm{kg}$, atropine $0.1 \mathrm{mg} / \mathrm{kg}$ body weight, i.p.) were stereotaxically injected with $50 \mathrm{nl}(1 \mathrm{nmol})$ of a $20 \mathrm{mM} \mathrm{KA}$ solution (Tocris) in $0.9 \%$ sterile saline into the right dorsal hippocampus [coordinates relative to bregma: anterio-posterior $(\mathrm{AP})=-2.0 \mathrm{~mm}$, medio-lateral $(\mathrm{ML})=-1.4 \mathrm{~mm}$, dorso-ventral $(\mathrm{DV})=-1.8 \mathrm{~mm}]$. Controls were injected with $0.9 \%$ saline. After recovery from anesthesia, mice were kept under observation for several hours. Behavioral status epilepticus (SE) was verified, characterized by mild convulsive movements, chewing, rotations or immobility, as previously described (Riban et al., 2002; Heinrich et al., 2006). Only mice that had experienced SE after KA injection were kept for further experiments.

\section{In situ Hybridization}

Localization of reelin mRNA was performed by in situ hybridization (ISH) with digoxigenin (DIG)-labeled cRNA probes as described earlier (Haas et al., 2002; Heinrich et al., 2006). Three weeks after KA injection, mice were deeply anesthetized (see above), transcardially perfused for $10 \mathrm{~min}$ with paraformaldehyde (PFA) in $0.1 \mathrm{M}$ phosphate buffer (PB), $\mathrm{pH}$ 7.4, followed by post-fixation of isolated brains for $4 \mathrm{~h}$ at $4^{\circ} \mathrm{C}$ in PFA, cryoprotection (20\% sucrose in $\mathrm{PB}$ overnight at $\left.4^{\circ} \mathrm{C}\right)$ and sectioning $(50 \mu \mathrm{m}$; coronal plane) on a cryostat. 
Slices were collected in culture dishes containing $2 \mathrm{x}$ SSC ( $1 \mathrm{x}$ $\mathrm{SSC}=0.15 \mathrm{M} \mathrm{NaCl}$ and $0.015 \mathrm{M}$ sodium citrate, $\mathrm{pH} 7.0$ ), followed by incubation with a 1:1 mixture of 2x SSC and hybridization buffer (50\% formamide, $4 \mathrm{x} \mathrm{SSC}, 50 \mathrm{mM} \mathrm{NaH}{ }_{2} \mathrm{PO}_{4}$, $250 \mu \mathrm{g} / \mathrm{ml}$ heat-denaturated salmon sperm DNA, $100 \mu \mathrm{g} / \mathrm{ml}$ tRNA, 5\% dextransulfate, 1\% Denhardt's solution) for $15 \mathrm{~min}$. Prehybridization in hybridization buffer for $50 \mathrm{~min}$ at $45^{\circ} \mathrm{C}$ was followed by hybridization in the same buffer supplemented with DIG-labeled antisense reelin cRNA probe $(100 \mathrm{ng} / \mathrm{ml})$ at $45^{\circ} \mathrm{C}$. Brain sections were washed twice in $2 \mathrm{x} \mathrm{SSC}$, followed by stringent washing at $55^{\circ} \mathrm{C}$ with $2 \mathrm{x}$ SSC and $50 \%$ formamide, $0.1 \mathrm{x}$ SSC and $50 \%$ formamide, and $0.1 \times$ SSC. Immunological detection of the hybrids was performed with an anti-DIG antibody conjugated with alkaline phosphatase and nitroblue tetrazolium and 5-bromo-4-chloro-3-indolyl phosphate as substrates. Tissue sections were mounted on slides, air dried, and embedded in Kaiser's gelatine (Roche).

\section{Quantification of Reelin mRNA-Expressing Neurons and Correlation with GCL Width}

Reelin mRNA-expressing neurons were quantified in the whole hippocampus of control animals (NaCl-injected) and after KA injection. Cells were counted at three positions along the septohippocampal axis (septal, intermediate, and temporal). Cell numbers were determined in two regions of interest (ROI) per section: ROI1 included the strata moleculare, lacunosum moleculare and radiatum, whereas ROI2 comprised the hilus (see Supplementary Figure S1). All reelin mRNA-expressing neurons were counted in each ROI using the ImageJ analysis software (NIH, public domain). Cell densities were determined in three sections per position by relating cell numbers to the area of the respective ROI. These data were imported to GraphPad Prism 5 software for statistical analysis.

Next, the mean GCL thickness was determined in the same tissue sections used for the quantification of reelin mRNAproducing neurons. Both GCL blades were subdivided into portions with constant thickness (see Supplementary Figure S2). Their width was measured with ImageJ. The respective values were multiplied with the length of the respective GCL portion. The multiplication-products from all CGL parts were summed up and divided by the total GCL length: (Length $1 \times$ Width $_{1}$ + Length $_{2} \times$ Width $_{2} \ldots+$ Length $_{n} \times$ Width $_{n}$ )/Total Length. Finally, the mean GCL thickness was correlated with the corresponding density of reelin mRNA-positive neurons in the hilus using GraphPad Prism 5 software. We fitted the curve of a non-linear regression analysis (exponential growth equation) into the data points, since we found this equation to be the most suitable approximation to the real data.

\section{Organotypic Hippocampal Slice Cultures}

Eight-days-old (P8) male and female Thyl-eGFP mouse pups were used for OHSC preparation as described previously (Chai et al., 2014). In brief, brains were removed from the skull following decapitation under isoflurane anesthesia. The hippocampi were dissected and sliced $(400 \mu \mathrm{m})$ perpendicular to the longitudinal axis of the hippocampus using a McIlwain tissue chopper. Only slices from the mid region of each hippocampus were used. The slices were placed onto culture inserts (Millipore) and transferred to 6-well plates with $1 \mathrm{ml} /$ well of nutrition medium containing 50\% minimal essential medium (MEM), 25\% basal medium Eagle (BME), 25\% heat-inactivated horse serum (Invitrogen) supplemented with $0.65 \%$ glucose and $2 \mathrm{mM}$ glutamate ( $\mathrm{pH}$ 7.2). OHSC were incubated as static cultures (Stoppini et al., 1991) in $5 \% \mathrm{CO}_{2}$ at $37^{\circ} \mathrm{C}$ for 7 days in vitro (DIV) before experiments started; the medium was changed every second day.

\section{Production and Purification of the Recombinant Reelin Fragment R3-6}

Human embryonic kidney 293 (HEK 293) cells were grown to subconfluency and were transiently transfected with an expression vector containing the myc-tagged R3-6 Reelin fragment (central fragment; Jossin et al., 2004; Bouché et al., 2013). One day after transfection, the fetal calf serum (FCS)containing cell culture medium was replaced by serumfree Dulbecco's modified Eagle's medium (DMEM; Invitrogen) supplemented with $1.0 \mathrm{~g} / \mathrm{l}$ glucose. After $2 \mathrm{DIV}$, the cell culture medium containing the R3-6 Reelin fragment was harvested and concentrated by centrifugation using $100 \mathrm{kDa}$ cutoff centrifugal filters (Merck Millipore), sterile filtered, and stored at $-20^{\circ} \mathrm{C}$ until further use (Leemhuis et al., 2010).

Purity and size of the recombinant R3-6 Reelin fragment was confirmed by Western blot analysis. To this end, recombinant full length Reelin and R3-6 Reelin were size-fractionated by a $3-8 \%$ Tris-acetate sodium dodecyl sulfate-polyacrylamide gel electrophoresis (SDS-PAGE; Invitrogen) and blotted onto a polyvinylidene fluoride (PVDF) membrane (Roche). For immunodetection, the PVDF membrane was blocked with I-Block buffer (Tropix) and incubated with the monoclonal Reelin antibody R4B (2:1), produced in our laboratory as described by Jossin et al. (2007). It was followed by the incubation with the appropriate alkaline-phosphatase-conjugated secondary antibody (1:10,000; Tropix) and CDP Star (Tropix) was used as substrate for chemiluminescent detection by the Chemismart System (Peqlab Biotechnologies; see Supplementary Figure S3).

\section{Concentration Assessment of the Recombinant R3-6 Reelin Fragment}

The concentration of the recombinant R3-6 Reelin fragment was assessed by a dot blot assay followed by immunofluorescence detection. In brief, recombinant mouse Reelin protein with a known concentration (100 $\mu \mathrm{g} / \mathrm{mL}, \mathrm{R} \& \mathrm{D}$ Systems) and purified recombinant R3-6 Reelin were serially diluted and spotted onto nitrocellulose membrane (Santa Cruz Biotechnology). For immunodetection, the membrane was probed with the same antibody as for the Western blot, followed by incubation with the respective alkaline-phosphatase-conjugated secondary antibody (1:10,000; Tropix). CDP Star (Tropix) was used as substrate for chemiluminescent detection by the Chemismart System. Densitometric evaluation of the dot blot signals was performed by optical density (OD) measurement using ImageJ software. 
The concentration was calculated based on the comparison of OD values obtained for the recombinant mouse Reelin standard curve and the recombinant R3-6 Reelin fragment.

\section{Immunohistochemistry}

Tissue sections $(50 \mu \mathrm{m})$ from perfused KA-injected mouse brains (see above) or whole OHSC from Thy1-eGFP mice were immunolabeled using a free-floating protocol (Heinrich et al., 2006; Tinnes et al., 2011). OHSC (13 DIV) were fixed with $4 \%$ PFA in PB (4 h, RT). After pre-incubation (0.25\% Triton X$100,10 \%$ normal serum in $\mathrm{PB}, 2 \mathrm{~h}$ ), tissue sections or slices were incubated for $24 \mathrm{~h}$ (RT) with mouse monoclonal antiReelin antibody (G-10, 1:1000; Chemicon) or rabbit polyclonal anti-Prox1 (1:1000, Abcam). Antibody binding was visualized by incubation with an appropriate Cy3-conjugated secondary antibody (1:400, Jackson ImmunoResearch Laboratories) in the dark (6 h, RT). Tissue sections were counterstained with DAPI. Sections and whole slices were coverslipped with anti-fading mounting medium (IMMU-Mount, Thermo Fisher Scientific) and analyzed using an epifluorescence (Axio Imager 2, Carl Zeiss) or confocal microscope (Olympus FluoView FV10i).

\section{Quantification of}

\section{Reelin-Immunofluorescence in OHSC}

Reelin-expressing neurons were quantified in whole slices under control conditions and after KA $(10 \mu \mathrm{M})$ application for $45 \mathrm{~min}$, followed by incubation in fresh medium for $8 \mathrm{~h}$. To quantify Reelin fluorescence intensity, confocal z-stacks were acquired from whole OHSC with an Olympus FV10i confocal laser scanning microscope (Olympus) using a 10x objective at high resolution $(1024 \times 1024$ pixel; $8 \times$ frame-average $)$ with constant exposure time and z-stack settings. Stacks were converted to grayscale and the signal intensity of Reelin immunolabeling along the hippocampal fissure (HF) and in the hilus was quantified as integrated density using the ImageJ analysis software. Values were corrected by background subtraction: integrated density - (measured area $\times$ mean background signal). The mean background was calculated for each experiment and for both areas of the HF and hilus. Background signals were measured in areas without Reelin signal.

\section{Live Cell Imaging}

Organotypic hippocampal slice cultures were prepared from Thy1-eGFP mouse pups (P8) and cultivated for 7-18 DIV. Immediately before live cell imaging, OHSC were exposed to KA ( 3 or $10 \mu \mathrm{M}$ ) for $45 \mathrm{~min}$, followed by addition of fresh medium or fresh medium including recombinant R3-6 Reelin fragment $(1 \mathrm{nM})$ followed by live cell imaging for $8 \mathrm{~h}$. For imaging, OHSC were placed, on the stage of a Leica SP2 confocal microscope, and enclosed in an aerated chamber at $37^{\circ} \mathrm{C}$ and with humidified atmosphere containing 5\% $\mathrm{CO}_{2}$. eGFP-positive granule cells were imaged along the Z-axis with a spacing of $6 \mu \mathrm{m}$, using a 10x objective at $2 \mathrm{x}$ optical zoom, at $45 \mathrm{~min}$ intervals over a period of $8 \mathrm{~h}$. To monitor the positions of individual granule cells, confocal image stacks taken at the different time points were imported into the image analysis software Fiji, which is based on
ImageJ (NIH, public domain). Using the $M$ track ${ }^{\odot}$ plugin (Erik Meijering), six individual granule cells/OHSC were randomly selected. Their positions were marked at all 10 time points over a period of $8 \mathrm{~h}$ to allow for the calculation of their migration distances.

To investigate preferred directions of migration, we identified individual granule cells in the superficial and deep GCL (three cells per sublayer/OHSC) after exposure to KA or control conditions. Cell motility was quantified by calculating the total length of the traveled path over $8 \mathrm{~h}$ and the effective distance of the migration as the length of the resulting vector between start and end point of the cell. To differentiate the direction of migration, we marked the border between the hilus $(\mathrm{H})$ and GCL and calculated the distance of the start and end point of the cells to this hilar-GCL border. Cells that reduced their distance to the border over time $\left[\mathrm{H}_{\text {distance }}(t=0 \mathrm{~min})-\right.$ $\left.\mathrm{H}_{\text {distance }}(t=450 \mathrm{~min})\right]$ were considered to migrate toward the hilus, whereas cells showing an increased distance in relation to the hilar-GCL border moved toward the molecular layer (ML). We used custom Matlab ${ }^{\circledR}$ software to perform this data analysis $\left(\right.$ Matlab $^{\circledast}$ 2014a, The-Mathworks).

\section{Statistical Analysis}

All values are expressed as mean \pm standard error of the mean (SEM). All statistical analyses were performed with GraphPad Prism 5 software. Differences between groups were tested for statistical significance (Student's $t$-test or one-way ANOVA with Tukey's multiple comparison test). Significance levels were set to ${ }^{*} P<0.05,{ }^{* *} P<0.01$, and ${ }^{* * *} P<0.001$.

\section{RESULTS}

\section{Quantification of Reelin mRNA-Expressing Neurons Along the Septotemporal Axis After Intrahippocampal KA Injection}

In previous studies, a loss of reelin-producing neurons has been shown in the septal hippocampus after KA injection on the mRNA and protein level (Heinrich et al., 2006; Antonucci et al., 2008; Duveau et al., 2011). Yet, these reports focused only on the area close to the KA injection site. There is, however, a septotemporal gradient of GCD and cell loss in the intrahippocampal KA mouse model (Häussler et al., 2012; Marx et al., 2013). Therefore, we aimed at precisely determining the spatial distribution of reelin-expressing neurons along the septotemporal axis of the hippocampus after KA injection by ISH and immunohistochemistry. To this end, reelin mRNA-positive neurons were counted in tissue sections at three positions (septal, intermediate, and temporal) along the hippocampal septotemporal axis at 21 days after KA injection, a time point when GCD has fully developed (Heinrich et al., 2006) and we correlated the GCL width with the number of reelin mRNA-positive hilar neurons. $\mathrm{NaCl}$-injected mice were used as controls (see Materials and Methods, Supplementary Figure S1). 
In tissue sections of control animals, many reelin mRNAexpressing neurons were observed in stratum oriens, stratum lacunosum moleculare along the $\mathrm{HF}$ and in the hilus at all positions along the septotemporal axis of the hippocampus (Figures 1A,C,E). After KA injection, a drastic loss of reelin mRNA- and Reelin-expressing neurons was evident all over the ipsilateral septal hippocampus, only at the HF, reelin mRNAand Reelin-positive neurons were preserved (Figures 1B,I). Interestingly, this loss was confined to the septal portion of the hippocampus, where GCD was present (Figures 1B,D,F,I-K). Cell counting revealed that the density of reelin mRNAexpressing neurons was decreased ipsilaterally at the $\mathrm{HF}$ at all three positions when compared to controls (septal; control: $228.5 \pm 31.26$, KA: $194.0 \pm 12.6$; intermediate; control: $165 \pm 24.45, \mathrm{KA}: 132 \pm 7.1$; temporal; control: $188 \pm 9.9$, KA: $147.0 \pm 8.6$ cells $/ \mathrm{mm}^{2}$ ), but this decrease did not reach significance (Figure 1G). In the hilus, however, an almost complete loss of reelin mRNA-synthetizing neurons was detectable in sections of the septal and intermediate KA-injected hippocampus when compared to controls (septal; control: $469.3 \pm 69.8$, KA: $22.92 \pm 3.2$; intermediate; control: $413.2 \pm 56.1$, KA: $27.56 \pm 5.9$ cells $/ \mathrm{mm}^{2}$ ), whereas at the temporal position the loss was not significant in comparison to controls (temporal; control: $335.9 \pm 71.9$, KA: $209.6 \pm 15.56$ cells $/ \mathrm{mm}^{2}$; Figure $\mathbf{1 H}$ ). Next, we determined the GCL width ipsilaterally in the same tissue sections and related it to the number of reelin mRNA-positive hilar neurons. We found an inverse correlation of GCL width and number of reelin mRNAexpressing neurons in the hilus (Figure 1L).

In summary, our detailed quantification along the septotemporal axis revealed that the loss of reelin mRNApositive neurons was strongest in the hilus in regions exhibiting GCD and this loss precisely correlates with the occurrence of GCD.

\section{Distribution of Reelin-Expressing Neurons in KA-Treated OHSC}

Next, we used OHSC from transgenic Thyl-eGFP mice to investigate the effect of the KA treatment on Reelin-producing neurons in vitro. KA $(10 \mu \mathrm{m})$ was applied to OHSC for $45 \mathrm{~min}$, followed by incubation in fresh medium for $8 \mathrm{~h}$. Slices were fixed with PFA and whole OHSC were immunolabeled for Reelin. In control OHSC, eGFP-positive granule cells were densely arranged in a compact layer with dendrites extending into the ML; Reelin-positive neurons were located at the $\mathrm{HF}$ and in the hilus (Figures 2A,C,E). In KA-treated OHSC, eGFP-positive granule cells appeared dispersed; there were still many Reelinimmunolabeled neurons at the HF, but almost all had disappeared from the hilus (Figures 2B,D,F). Densitometric evaluation revealed a slight reduction of Reelin immunofluorescence at the HF, but an almost complete, significant loss of the Reelin signal in the hilus (control: HF $25.46 \pm 3: 9 ; \mathrm{H} 7.99 \pm 2.4$; KA: HF $14.83 \pm 2.1$; $0.7 \pm 0.18$; Figures 2G,H). These results show that, like in vivo, Reelin-expressing neurons were lost in the hilus, whereas Reelin-synthetizing neurons at the HF survived.

\section{Life Cell Imaging of eGFP-Positive Granule Cells in OHSC After Treatment with Increasing Doses of KA}

As a prerequisite for later life cell imaging experiments, we first determined the minimal KA concentration needed to trigger migration. To this end, OHSC from Thyl-eGFP mice were exposed to 3 or $10 \mu \mathrm{M}$ KA for $45 \mathrm{~min}$, followed by incubation in fresh medium and life cell imaging for $8 \mathrm{~h}$ (Figures 3AC). Afterward, the migration distances of individual eGFPlabeled granule cells were determined (Figure 3D). We found that $3 \mu \mathrm{M} \mathrm{KA}(4.43 \pm 0.63 \mu \mathrm{m})$ increased the motility of eGFP-labeled granule cells only slightly above control values $(3.68 \pm 0.4 \mu \mathrm{m})$ during the observation period, whereas $10 \mu \mathrm{M}$ KA $(10.8 \pm 1.4 \mu \mathrm{m})$ triggered the movement significantly. Hence, we used this KA concentration for all subsequent imaging experiments.

\section{Migration Behavior of eGFP-Positive Granule Cells in OHSC After KA Treatment}

Next, we aimed at investigating whether eGFP-labeled granule cells followed a specific migration pattern triggered by KA treatment. As described above, we performed life cell imaging after KA $(10 \mu \mathrm{M})$ treatment and compared it to untreated controls. We randomly marked individual granule cells in the superficial and deep GCL (three cells per sublayer/OHSC) and tracked their position with respect to the border between the hilus and GCL (Figure 4A) over a period of $8 \mathrm{~h}$. We quantified differences in motility by calculating (1) the total length of the traveled path over $8 \mathrm{~h}$ and (2) the effective distance of migration as the length of the vector between start $(t=0 \mathrm{~min})$ and end point $(t=450$ min; Figure 4B).

This analysis revealed that after KA treatment granule cells showed a significantly higher motility than under control conditions with an increased total path length $(\mathrm{Ctrl}=5.10 \pm 0.65 \mu \mathrm{m}$; $\left.\mathrm{KA}=13.86 \pm 0.84 \mu \mathrm{m} ; P<1.73 \times 10^{-10}\right)$ and an increased effective distance $(\mathrm{Ctrl}=3.10 \pm 0.36 \mu \mathrm{m} ; \mathrm{KA}=5.59 \pm 0.49 \mu \mathrm{m}$; $\left.P<2.6 \times 10^{-4}\right)$. Furthermore, we found that the total path length increased correspondingly with the length of the effective path (Figure 4C). In addition, we observed that the majority of granule cells from KA-treated slices (80\%) migrated toward the hilus (Figures 4D,E), regardless of their initial position within the GCL (Figure 4F). Moreover, cells migrating toward the hilus traveled longer distances than those heading to the ML (changed distance to hilus, $\mathrm{Ctrl}=0.76 \pm 0.46 \mu \mathrm{m} ; \mathrm{KA}=3.17 \pm 0.85 \mu \mathrm{m} ; P<0.02$; Figure 4C).

\section{Influence of the Recombinant R3-6 Central Reelin Fragment on KA-Induced Motility of eGFP-Labeled Granule Cells}

So far, our results showed that in KA-treated OHSC Reelinexpressing neurons are mainly lost in the hilus and that the majority of eGFP-positive granule cells migrate toward the hilus. Together, these findings point to a stop signal function of Reelin 


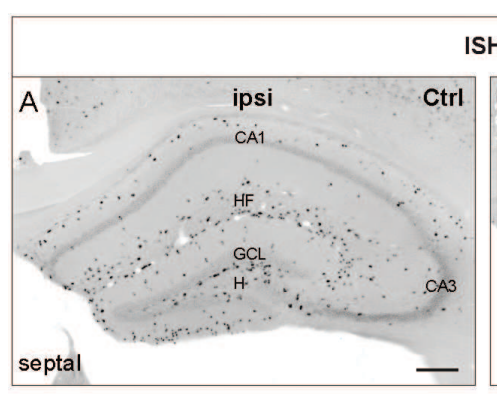

ISH
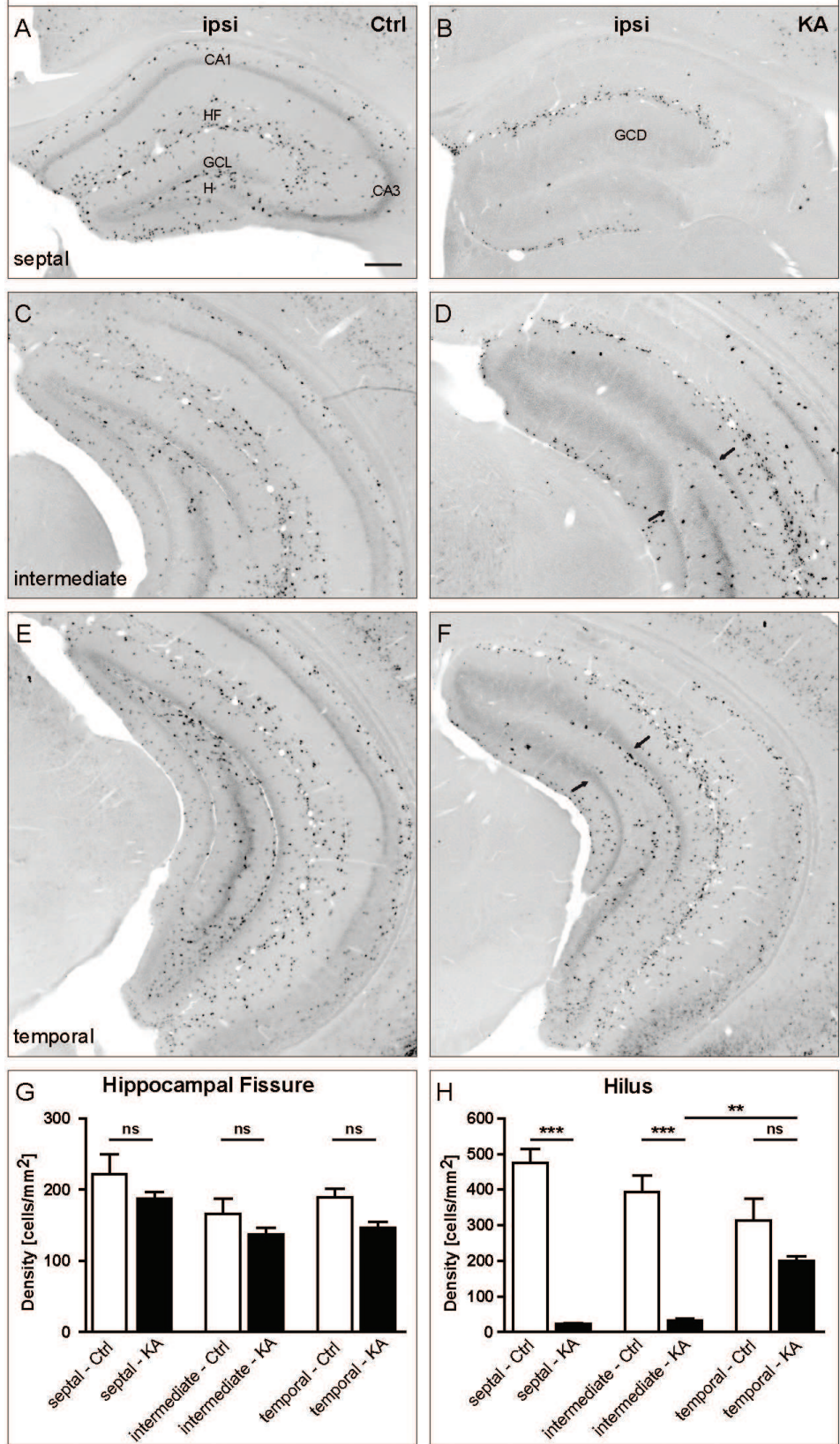
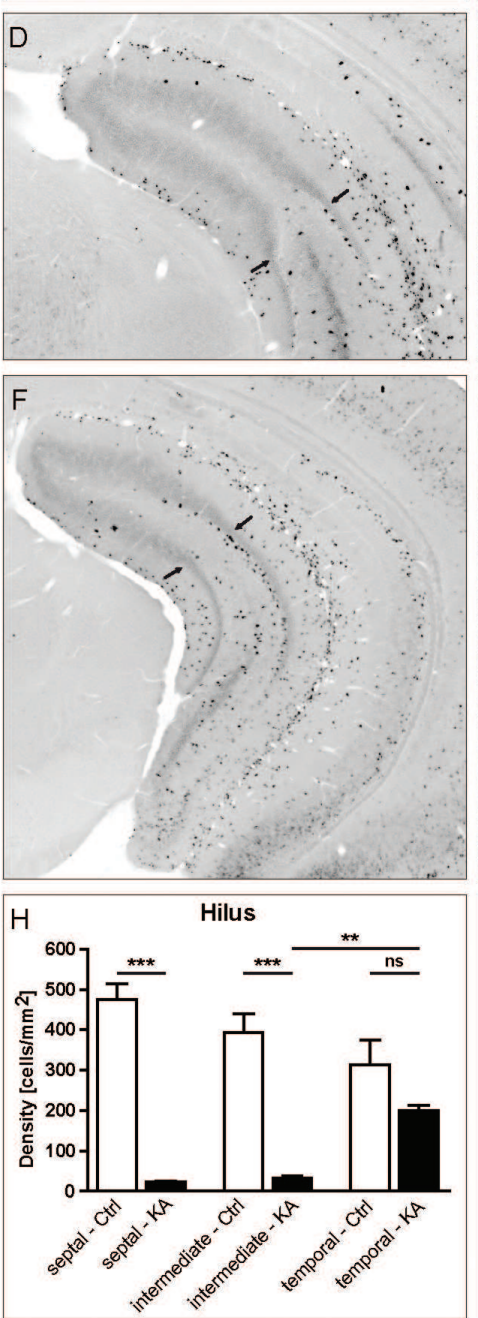
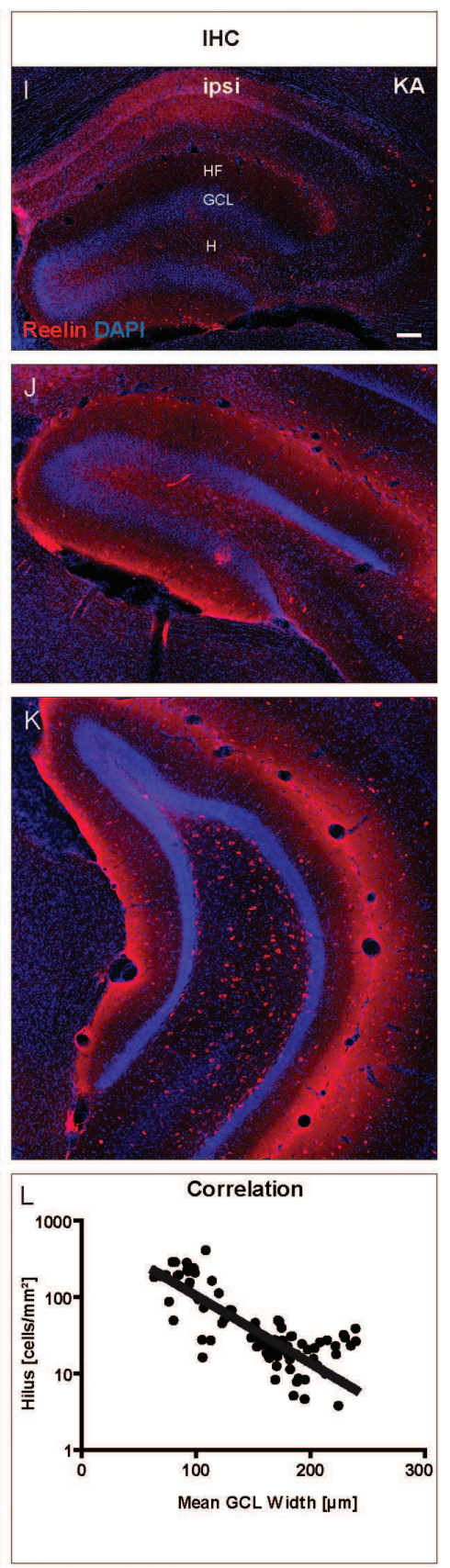

FIGURE 1 | Loss of reelin mRNA-expressing neurons coincides with GCD formation after unilateral intrahippocampal KA injection in adult mice. ISH for reelin mRNA was performed on tissue sections along the septotemporal axis at 21 days after KA injection. (A-F) Representative images showing the distribution of reelin mRNA-positive neurons in sections of the septal $(\mathbf{A}, \mathbf{B})$, intermediate $\mathbf{( C , D )}$ and temporal $\mathbf{( E , F )}$ portions of the hippocampus of control animals $(\mathbf{A}, \mathbf{C}, \mathbf{E})$ and ipsilateral to the KA injection (B,D,F). (A,C,E) In controls, many reelin mRNA-expressing neurons are present in the stratum oriens, stratum lacunosum moleculare, along the HF and in the hilus at all three positions along the septotemporal axis of the hippocampus (septal, intermediate, and temporal). (B) At 21 days after intrahippocampal KA injection there is a drastic loss of reelin mRNA-expressing neurons all over the ipsilateral septal hippocampus, where GCD is present. Only at the HF, they are preserved. (D,F) A loss of reelin mRNA-positive neurons can also be observed in intermediate and temporal sections, however, being confined to the portion with GCD. Arrows indicate the transition from GCD to normal GCL, where reelin mRNA-positive neurons reappear. (G,H) Quantification of the number of reelin mRNA-expressing neurons in the HF (G) and the hilus $\mathbf{( H )}$ in controls $(n=3)$ and after KA injection $(n=5)$ at three different positions along the septotemporal axis of the hippocampus (septal, intermediate, and temporal). Note the significant loss of reelin mRNA-expressing neurons in the hilus at septal and intermediate positions. One-way ANOVA followed by Tukey's Multiple Comparison Test $\left({ }^{* *} P<0.01\right.$; $\left.{ }^{* * *} P<0.001\right)$. Representative images of tissue sections immunolabeled for Reelin (red) counterstained with DAPI (blue) of the septal (I), intermediate ( $\mathbf{J})$, and temporal (K) portions of the hippocampus ipsilateral to the KA injection. Like on the mRNA level, Reelin-expressing neurons are gone in the septal and intermediate hilus but are preserved at the HF. They reappear in the temporal hippocampus, mirroring the distribution of reelin mRNA expression. (L) Graph showing the correlation of the mean GCL width with the number of reelin mRNA-positive hilar neurons $\left(r^{2}=0.6112\right)$. CA1, cornu ammonis 1; CA3, cornu ammonis 3; HF, hippocampal fissure; GCL, granule cell layer; H, hilus; ML, molecular layer. Scale bars: 200 um. 

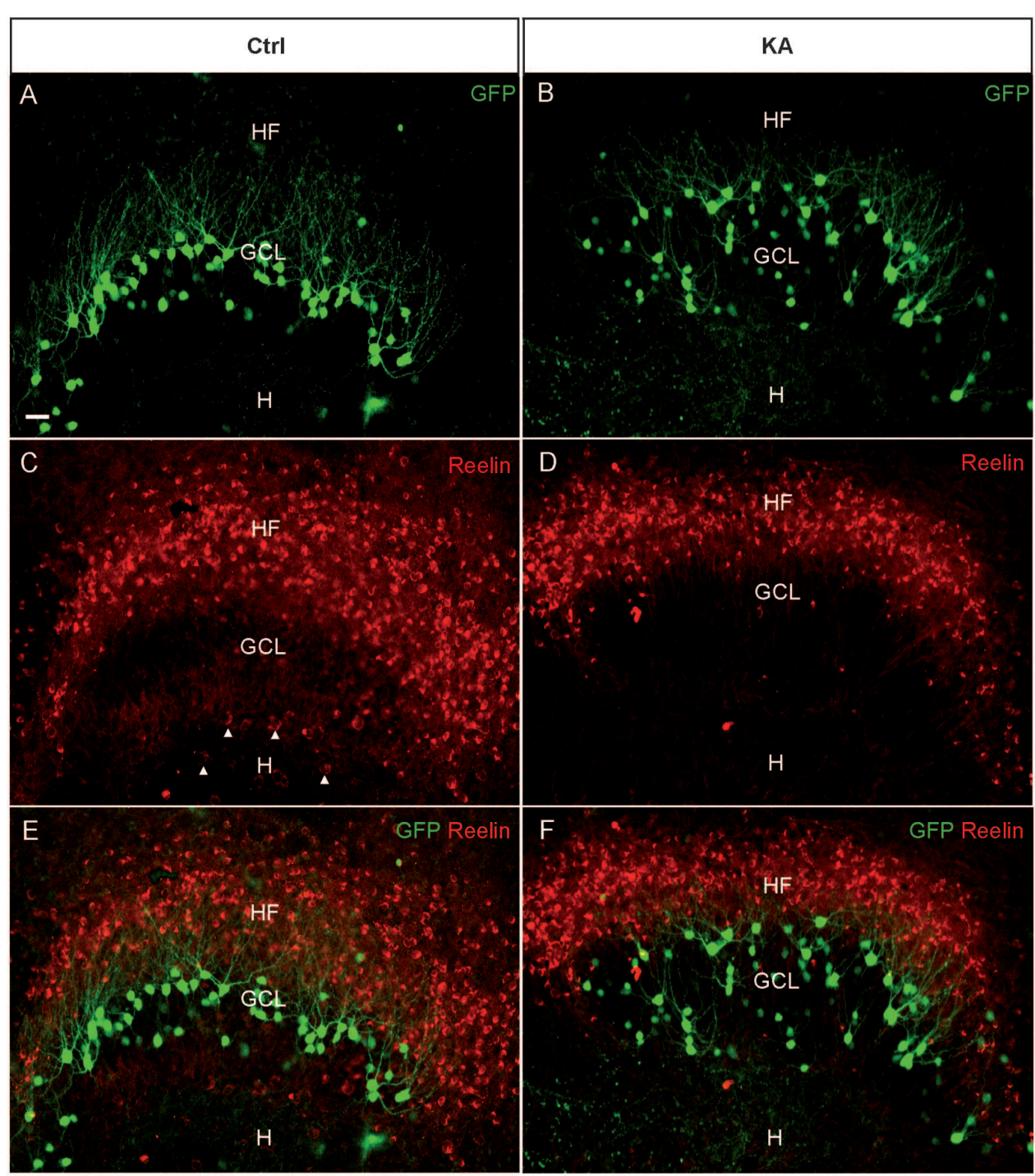

G

$\mathrm{H}$

Hippocampal Fissure

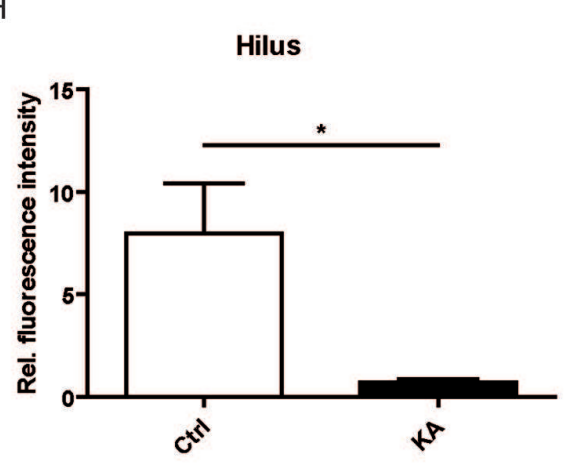

FIGURE 2 | Loss of Reelin-positive neurons in the hilus after KA treatment in OHSC. Representative confocal images of whole OHSC from Thy1-eGFP (enhanced green fluorescent protein; green) mice immunolabeled for Reelin (red). (A,C,E) Control. (B,D,F) OHSC, $8 \mathrm{~h}$ after KA application for 45 min. In the control, eGFP-positive granule cells are arranged in a compact layer (A) but appear dispersed after KA treatment (B). (C,D) Immunolabeling for Reelin. Many strongly immunostained Reelin-expressing neurons are visible at the HF, and large Reelin-immunopositive neurons are located in the hilus (arrow heads, C). Note the loss of Reelin-positive hilar interneurons after KA treatment (D). (E,F) Overlay of eGFP (green) and Reelin (red) signals. (G,H) Densitometric quantification of the Reelin signal at the $\mathrm{HF}(\mathbf{G})$ and in the hilus $\mathbf{( H )}$ in controls $(n=4)$ and after KA treatment $(n=4)$. Unpaired student's $t$-test $(* P<0.05$, ns with $P=0.057)$. GCL, granule cell layer; $H$, hilus; HF, hippocampal fissure. Scale bar: $10 \mu \mathrm{m}$. 


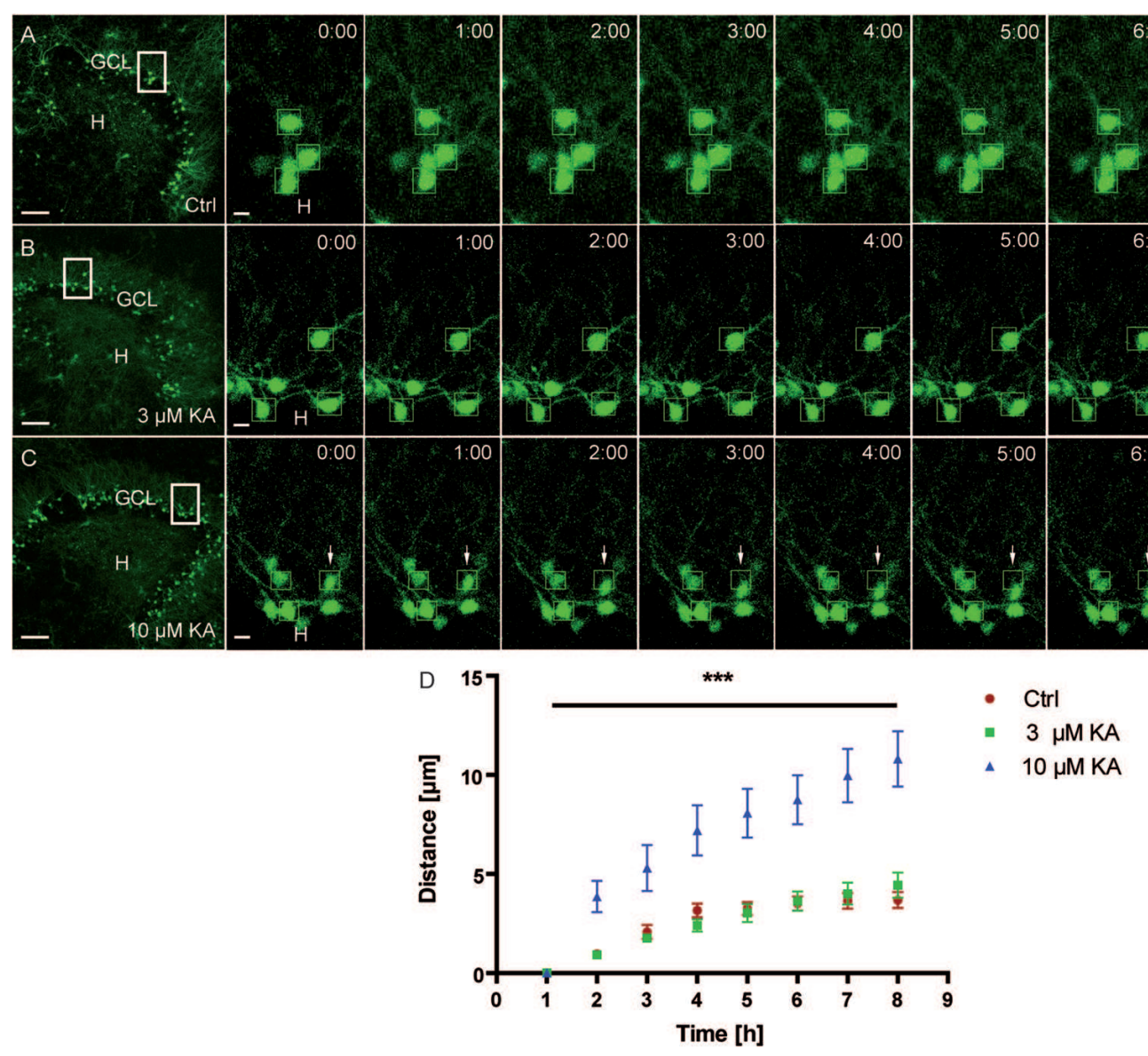

FIGURE 3 | Motility of granule cells depends on the KA concentration. Life cell imaging of individual eGFP-labeled granule cells was performed over a period of $8 \mathrm{~h}$, and migration distances of randomly selected cells were assessed as described in Section "Materials and Methods." Representative confocal micrographs of nine imaging time points are shown for each condition. Left panel: overview; white frame indicates the area shown at high magnification on the right. Tracked cells, are marked by green frames. (A) Control $(n=4 ; 24$ cells). Cells remain in place. (B) $3 \mu \mathrm{M} \mathrm{KA}(n=4 ; 24$ cells). Tracked cells behave similar to controls. (C) $10 \mu \mathrm{M} \mathrm{KA}$ ( $n=3,18$ cells). Granule cells show increased motility (white arrows). (D) Statistical analysis of the motility of adult granule cells of control and KA-treated OHSC $(3 \mu \mathrm{M}$ KA, $10 \mu \mathrm{M})$. The migration behavior increases in a KA dose-dependent manner over the entire $8 \mathrm{~h}$ period. One-way ANOVA followed by Tukey's test with $(* * * P<0.001)$. GCL, granule cell layer; $\mathrm{H}$, hilus. Scale bars: $80 \mu \mathrm{m}$ for overview; $5 \mu \mathrm{m}$ for high magnifications.

which might be lost in the presence of KA. Thus, we next investigated whether the R3-6 central Reelin fragment, known to be important for activation of the Reelin signaling cascade (Jossin et al., 2004), would be capable of preventing the observed KA-triggered movement of granule cells. For this purpose, OHSC were treated for $45 \mathrm{~min}$ with $\mathrm{KA}$, followed by washout, addition of the recombinant R3-6 Reelin fragment to the medium and subsequent live cell imaging for $8 \mathrm{~h}$.

As shown before, KA treatment alone caused an increased motility $(10.4 \pm 1.4 \mu \mathrm{m})$ of granule cells when compared to the controls $(3.9 \pm 0.4 \mu \mathrm{m}$; Figures $5 \mathbf{A}, \mathbf{B})$. In contrast, the presence of the R3-6 Reelin fragment significantly prevented the movement of granule cells $(4.2 \pm 0.5 \mu \mathrm{m})$ when compared with KA-treated OHSC (Figures 5C-E). As a control, we showed that the application of KA and the R3-6 Reelin fragment did not prevent the KA-mediated loss of Reelin-positive hilar neurons (see Supplementary Figure S4). These results indicate that the central Reelin fragment was able to stop the KA-mediated migration of eGFP-positive granule cells and support the role for Reelin as a positional signal for granule cells in the adult hippocampus.

\section{DISCUSSION}

In this study, we show that reelin-producing neurons are mainly lost in the hilus after intrahippocampal KA injection in mice and that this loss correlates precisely with the occurrence of GCD. Also in OHSC, KA treatment causes a rapid and complete loss of hilar, Reelin-producing neurons. Using life cell microscopy, we provide evidence that differentiated eGFP-positive granule cells actively migrate toward the Reelin-free hilar region, and that this migration process can be prevented by application of the recombinant R3-6 Reelin fragment. Thus, the development of the GCD seems to depend on the loss of functionally active Reelin. 
A

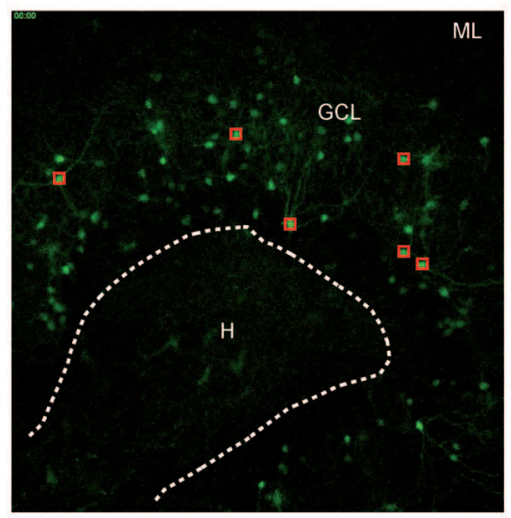

B

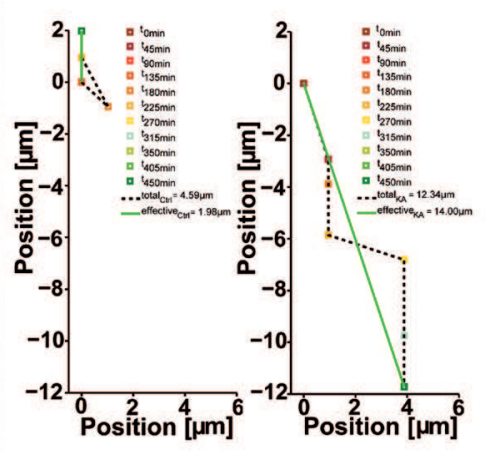

E

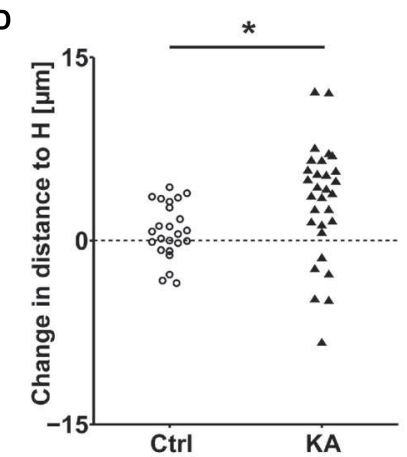

C

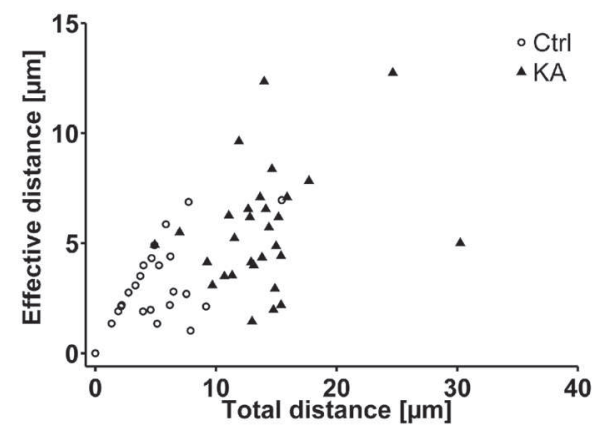

F

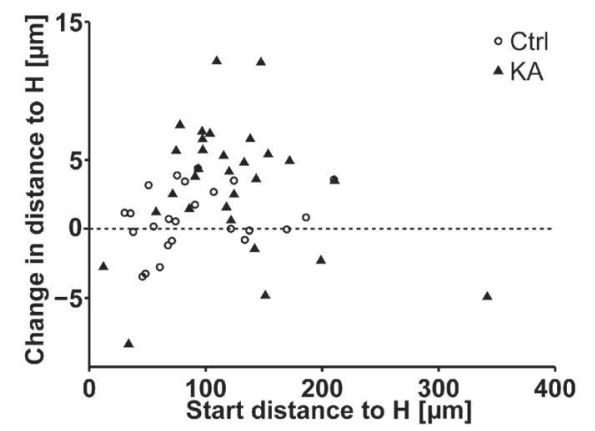

FIGURE 4 | EGFP-positive granule cells migrate preferentially to the hilus. Life cell imaging of individual eGFP-labeled granule cells in the superficial and deep granule cell layer after exposure to KA and in controls over a period of $8 \mathrm{~h}$. (A) Representative photomicrograph of a KA-treated OHSC from a Thy-1 eGFP mouse ( $t=0 \mathrm{~min}$ ). Red squares indicate the initial position of monitored cells. White dashed line marks the border between the hilus and the GCL, taken as reference to calculate the relative migration distances of individual eGFP-labeled cells. (B) Representative graphs showing the motility of one tracked neuron in a control (left graph) or a KA-treated OHSC (right graph). Cell motility was assessed by calculating both, the total length of the traveled path over $8 \mathrm{~h}$ (black dashed line $=$ total distance) and the effective distance of the migration as the length of the resulting vector (green solid line) between start (at $x=0$; $t=0$ min) and end point ( $t=450$ min). (C) Diagram showing the relation between total and effective migration distance of all tracked granule cells. In contrast to controls, all cells change their position after KA treatment. (D) Migration distances of all tracked individual granule cells with respect to the border between hilus and GCL in control $(n=4,24$ cells) and KA-treated OHSC ( $n=5,30$ cells). To differentiate the migration direction, we marked the border between the hilus and GCL (A, white dashed line) and calculated the distance of the start and end point of the cells to this border. Cells that reduce their distance to the border over time $\left[\mathrm{H}_{\text {distance }}\left(t=0\right.\right.$ min) $-\mathrm{H}_{\text {distance }}$ ( $t=450 \mathrm{~min}$ ), positive values] are considered migrating toward the hilus. Cells showing an increase in distance (negative values) moved toward the ML. Cells in KA-treated OHSC (black triangles) travel longer distances in both directions, toward ML and hilus, than controls (black circles). Two-sample Student's t-test $\left({ }^{*} P<0.05\right)$. Cells which migrate toward the hilus travel longer distances than those heading toward the ML. The majority of cells progresses toward the hilus. (E) Relative distribution of cells traveling toward the hilus (80\%) or molecular layer (20\%) in KA-treated OHSC. (F) Diagram showing the relation between initial distance to the hilus-GCL border and change in distance to the border of all tracked granule cells. In contrast to controls, all cells change their position after KA treatment and travel longer distances regardless of their position in the deep or superficial granule cell layer. ML, molecular layer; GCL, granule cell layer; $\mathrm{H}$, hilus.

\section{Loss of Reelin mRNA-Expressing Neurons Correlates Spatially with the Occurrence of GCD in the Epileptic Mouse Hippocampus}

In the hippocampus reelin mRNA and protein is mainly expressed by GABAergic interneurons located primarily in stratum oriens and radiatum of cornu ammonis (CA) 1 and CA3 and in the hilus of the dentate gyrus but also by CR cells located along the HF (Alcántara et al., 1998; Pesold et al., 1998; Ramos-Moreno et al., 2006). In the present study, we show by detailed quantification of reelin mRNA expression along the septotemporal axis of the epileptic mouse hippocampus that reelin mRNA-synthetizing $\mathrm{CR}$ cells at the $\mathrm{HF}$ survive, whereas in the hilus reelin mRNA-expressing interneurons are lost. In fact, this loss is confined to the septal hippocampus and precisely matches spatially with the occurrence of GCD, as demonstrated by correlating GCL width and numbers of reelin-synthesizing neurons. These results confirm and extend previous studies in the same epilepsy model, showing that Reelinproducing CR cells are preserved at the HF but lost in the hilus (Heinrich et al., 2006; Antonucci et al., 2008; Duveau et al., 2011). However, all these reports focused only on the area close to the KA injection site. Here, we demonstrate that the loss of Reelin synthesis precisely mirrors the septotemporal gradient of GCD described for this epilepsy model (Häussler et al., 2012) and highlight a link between Reelin loss and GCD formation. 


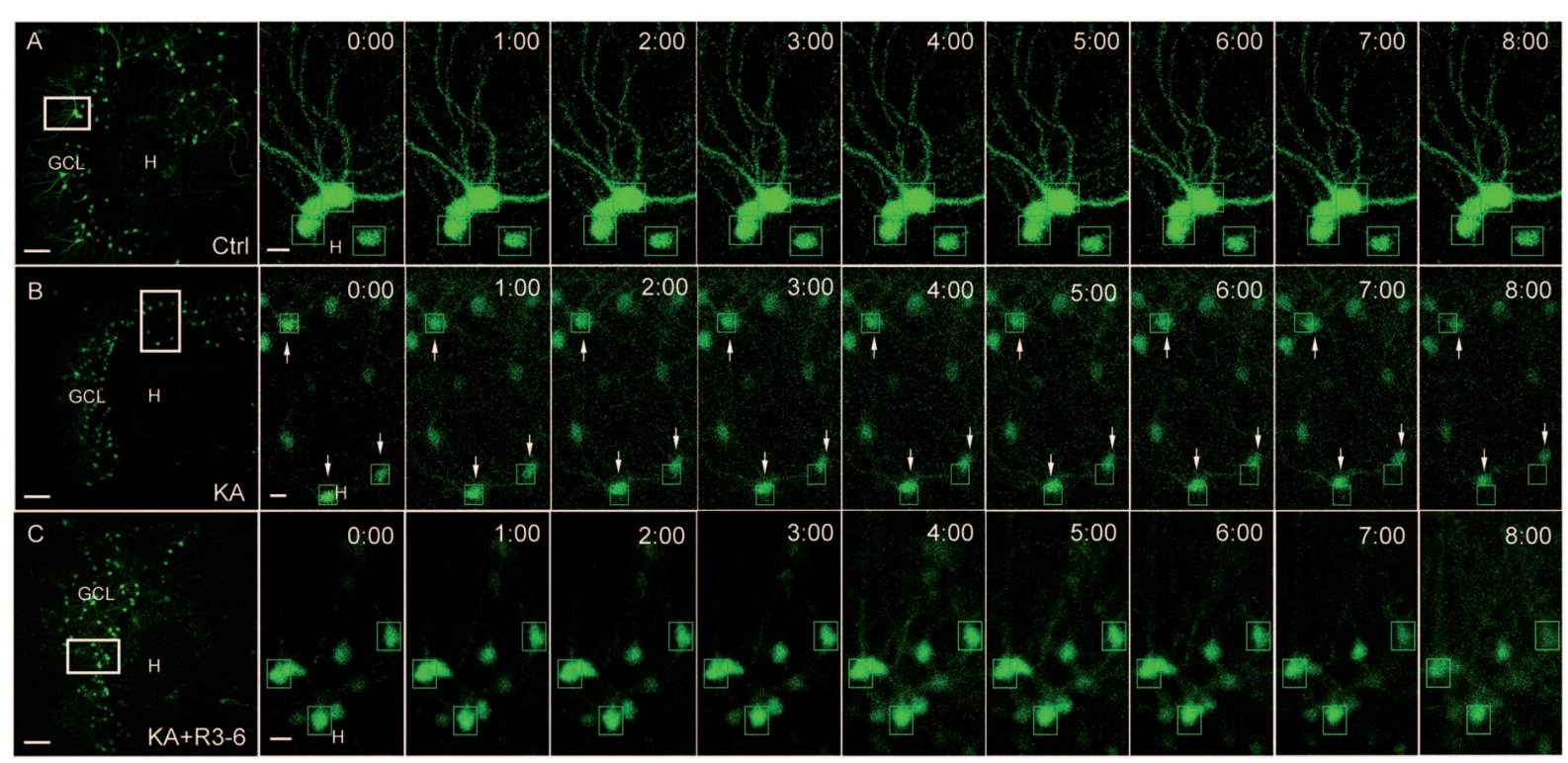

D

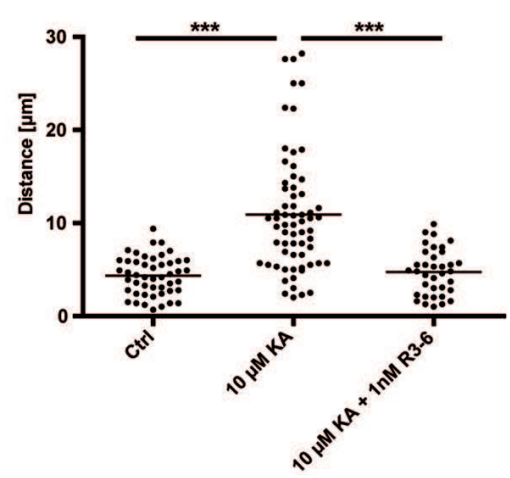

E

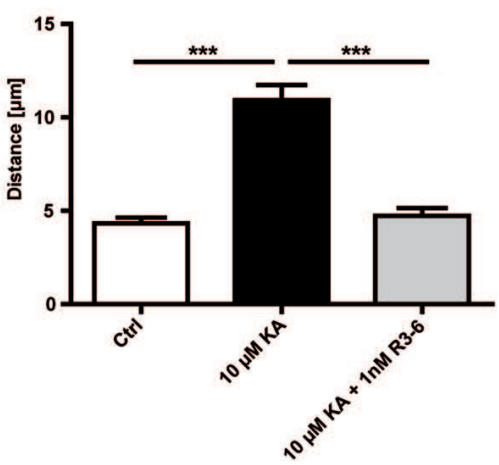

FIGURE 5 | Kainate-induced migration of differentiated granule cells is prevented by the central R3-6 Reelin fragment. Live cell imaging of individual eGFP-positive granule cells was performed over a period of $8 \mathrm{~h}$, and migration distances of randomly selected cells were assessed as described in Section "Materials and Methods." Representative confocal micrographs of nine imaging time points are shown for each condition. Left panel: overview; white frame indicates the area shown at high magnification on the right. Tracked cells are marked by green frames. (A) Untreated control ( $n=8 ; 48$ cells). Cells do not change position. (B) Treatment of OHSC with $10 \mu \mathrm{M} \mathrm{KA}$ for $45 \mathrm{~min}$ ( $n=10$; 60 cells). Granule cells (GCs) with high motility are indicated by arrows. (C) Treatment of OHSC with $10 \mu \mathrm{M}$ KA for $45 \mathrm{~min}$, followed by incubation with fresh medium and subsequent application of recombinant R3-6 Reelin fragment (1 nM; $n=6$; 36 cells). Like controls, cells do not change position. (D,E) Quantitative evaluation of migration distances of individual GCs. KA-treated GCs migrate, but not in the presence of the recombinant R3-6 Reelin fragment. One-way ANOVA, followed by Tukey's Multiple Comparison Test (***P < 0.001 ; Ctrl vs. $10 \mu \mathrm{M}$ KA + 1 nM R3-6 shows no significance). GCL, granule cell layer; $\mathrm{H}$, hilus. Scale bars: $80 \mu \mathrm{m}$ for overview; $5 \mu \mathrm{m}$ for high magnifications.

\section{KA Treatment of OHSC Causes a Rapid Loss of Reelin-Producing Neurons in the Hilus}

Organotypic hippocampal slice cultures have been shown to be a suitable model to study neuronal changes induced by epileptiform activity. Challenged by treatment with the glutamate receptor agonist KA, OHSC develop histopathological features similar to AHS such as cell death, mossy fiber sprouting, GCD, and epileptic activity (Routbort et al., 1999; Tinnes et al., 2011; Chai et al., 2014). Here we used OHSC obtained from Thy1eGFP mice, known to express eGFP primarily in a subset of differentiated granule cells as shown previously (Feng et al., 2000; Chai et al., 2014) and by double labeling with Prox1, a marker for differentiated granule cells (Supplementary Figure S5). When OHSC were exposed to KA for $45 \mathrm{~min}$, a rapid (within $8 \mathrm{~h}$ ) and selective loss of Reelin-positive interneurons was observed in the hilus, whereas Reelin-positive CR cells persisted. This observation confirms the high vulnerability of Reelin-producing interneurons to KA-mediated excitotoxicity seen in vivo and reported in OHSC previously (Tinnes et al., 2011; Chai et al., 2014), resulting in a Reelin loss confined to the hilar region. The observed difference in survival rate between interneurons and CR cells is most likely due to differential expression of glutamate receptors, since only hilar interneurons, but not CR cells, up-regulate c-Fos after KA treatment (Tinnes et al., 2011). 


\section{eGFP-Positive Granule Cells Preferentially Migrate toward the Reelin-Poor Hilus}

In the adult dentate gyrus, granule cells form a densely packed layer. Under epileptic conditions, the lamination can dissolve and result in GCD as observed, in MTLE patients (Houser, 1990; Haas et al., 2002) and in our MTLE mouse model (Bouilleret et al., 1999; Heinrich et al., 2006; Häussler et al., 2012). GCD formation is a process affecting differentiating granule cells, since GCD develops in the absence of neurogenesis as shown previously after intrahippocampal KA injection (Kralic et al., 2005; Heinrich et al., 2006; Nitta et al., 2008). Recent in vitro studies reported that this migration process is based on somal translocation (Murphy and Danzer, 2011; Chai et al., 2014). Somatic translocation is a principal migratory mechanism of neurons during brain development and occurs when the nucleus and perisomatic cytoplasm are displaced into a leading process (Rakic, 1972; Métin et al., 2008). Here, we show by life cell microscopy that eGFP-labeled, differentiated granule cells become motile in response to KA challenge. By tracking the path of individual neurons during the whole observation period, we found that the majority (80\%) moved in the direction of the hilus, whereas only $20 \%$ traveled to the opposite direction toward the ML. The migration pattern appeared rather complex. The neurons did not move straight into one direction but traveled erroneously in different directions before they reached a position closer to the hilar (or ML) area. It is tempting to speculate that most of the granule cells moved specifically to the direction of the Reelin-free hilar area. We cannot exclude, however, that a functional inactivation of Reelin by impaired proteolytic processing, known to occur under epileptic conditions (Tinnes et al., 2011, 2013), might play a role in the movement of neurons toward the ML.

\section{KA-Induced Motility of Adult Granule Cells is Prevented by Application of the Central R3-6 Reelin Fragment}

Reelin acts as a positional cue for dentate granule cells during development, since rescue of granule cell lamination in Reelin-deficient reeler mice could be achieved when Reelin was present in normotopic position, provided by a wild-type co-culture (Zhao et al., 2004). Conversely, infusion of Reelin-blocking antibodies (CR-50) into the hippocampus of normal adult mice induced GCD locally (Heinrich et al., 2006). These findings established a role for Reelin in stabilizing the lamination of the dentate gyrus. Accordingly, we hypothesized that the KA-triggered motility of dentate granule cells toward the Reelin-free hilar area might be caused by a loss of the positional cue. Granule cells constitutively express the Reelin receptors ApoER2 and VLDLR (Haas et al., 2002) and have been shown to maintain their expression after KA injection (Müller et al., 2009). Here, we demonstrated that addition of recombinant R3-6 Reelin fragment $(1 \mathrm{nM})$ was able to prevent the movement of granule cells observed after KA application alone. The R3-6 Reelin fragment has been shown to be sufficient for activating the Reelin signal transduction cascade on target cells (Jossin et al., 2004). Despite the existence of several Reelin isoforms in vivo, only fragments containing R3-6 are capable of binding ApoER2 and VLDLR, and both receptors alone are capable of binding Reelin with similar affinity. The residues Lys-2360 and Lys-2467, found in Reelin R3-6, are directly responsible for coordinated binding of Reelin to the conserved ligand binding domains of ApoER2/VLDLR (Yasui et al., 2007, 2010). In agreement with these findings, application of Reelin fragments containing R5-6 to reeler cortical explants is sufficient to induce Dab1 phosphorylation and to normalize cortical lamination (Jossin et al., 2004).

So far, our findings point to a stop signal function of Reelin, which might be lost in the presence of KA. In contrast, a recent study did not detect the formation of GCD after conditional Reelin knockout in the adult dentate gyrus (Lane-Donovan et al., 2015). In these mice, however, Reelin was not ablated completely; they still exhibited around 5\% of the initial Reelin concentration. Since very low Reelin concentrations (1 nM) were sufficient to obtain significant effects in our hands and also in other studies (Leemhuis et al., 2010), the incomplete Reelin knockout may explain the controversy.

Thus, our results indicate that the central Reelin fragment is able to prevent the KA-mediated migration of eGFP-positive granule cells and support the role for Reelin as a positional signal for granule cells in the adult hippocampus.

\section{AUTHOR CONTRIBUTIONS}

CO: performed experiments, data analysis, manuscript writing; GM: performed experiments, data analysis; JG: performed experiments, data analysis; AK: data analysis and Matlab ${ }^{\circledR}$ calculations; MF: confocal imaging and data analysis; UE: data analysis; $\mathrm{CH}$ : conception, supervision, manuscript writing.

\section{FUNDING}

This work was financially supported by the German Research Council (DFG) as part of the Cluster of Excellence 'BrainLinksBrainTools' (EXC1086), by the German Federal Ministry of Education and Research (BMBF) (Bernstein Focus Neurotechnology Freiburg*Tuebingen, FKZ 01GQ0830), by ERA-Net NEURON II CIPRESS and by a fellowship of the German Academic Exchange Service (DAAD) to CO. The article processing charge was funded by the German Research Foundation (DFG) and the University of Freiburg in the funding programme Open Access Publishing. 


\section{ACKNOWLEDGMENTS}

We are grateful to S. Huber and A. Djie-Maletz for excellent technical assistance and to Dr. H. Bock, University of Düsseldorf, for plasmids and reagents.

\section{REFERENCES}

Alcántara, S., Ruiz, M., D’Arcangelo, G., Ezan, F., De Lecea, L., Curran, T., et al. (1998). Regional and cellular patterns of reelin mRNA expression in the forebrain of the developing and adult mouse. J. Neurosci. 18, 7779-7799.

Antonucci, F., Garbo, A., Novelli, E., Manno, I., Sartucci, F., Bozzi, Y., et al. (2008). Botulinum neurotoxin $\mathrm{E}$ (BoNT/E) reduces CA1 neuron loss and granule cell dispersion, with no effects on chronic seizures, in a mouse model of temporal lobe epilepsy. Exp. Neurol. 210, 388-401. doi: 10.1016/j.expneurol.2007.11.012

Bouché, E., Romero-Ortega, M. I., Henkemeyer, M., Catchpole, T., Leemhuis, J., Frotscher, M., et al. (2013). Reelin induces EphB activation. Cell. Res. 23, 473-490. doi: 10.1038/cr.2013.7

Bouilleret, V., Ridoux, V., Depaulis, A., Marescaux, C., Nehlig, A., and Le Gal La Salle, G. (1999). Recurrent seizures and hippocampal sclerosis following intrahippocampal kainate injection in adult mice: electroencephalography, histopathology and synaptic reorganization similar to mesial temporal lobe epilepsy. Neuroscience 89, 717-729. doi: 10.1016/S0306-4522(98)00401-1

Chai, X., Münzner, G., Zhao, S., Tinnes, S., Kowalski, J., Häussler, U., et al. (2014). Epilepsy-induced motility of differentiated neurons. Cereb. Cortex 24, 2130-2140. doi: 10.1093/cercor/bht067

D’Arcangelo, G., Homayouni, R., Keshvara, L., Rice, D. S., Sheldon, M., and Curran, T. (1999). Reelin is a ligand for lipoprotein receptors. Neuron 24, 471-479. doi: 10.1016/S0896-6273(00)80860-0

D’Arcangelo, G., Miao, G. G., Chen, S. C., Soares, H. D., Morgan, J. I., and Curran, T. (1995). A protein related to extracellular matrix proteins deleted in the mouse mutant reeler. Nature 374, 719-723. doi: 10.1038/374719a0

Duveau, V., Madhusudan, A., Caleo, M., Knuesel, I., and Fritschy, J. M. (2011). Impaired reelin processing and secretion by Cajal-Retzius cells contributes to granule cell dispersion in a mouse model of temporal lobe epilepsy. Hippocampus 21, 935-944. doi: 10.1002/hipo.20793

Feng, G., Mellor, R. H., Bernstein, M., Keller-Peck, C., Nguyen, Q. T., Wallace, M., et al. (2000). Imaging neuronal subsets in transgenic mice expressing multiple spectral variants of GFP. Neuron 28, 41-51. doi: 10.1016/S0896-6273(00) 00084-2

Frotscher, M., Haas, C. A., and Förster, E. (2003). Reelin controls granule cell migration in the dentate gyrus by acting on the radial glial scaffold. Cereb. Cortex 13, 634-640. doi: 10.1093/cercor/13.6.634

Gong, C., Wang, T. W., Huang, H. S., and Parent, J. M. (2007). Reelin regulates neuronal progenitor migration in intact and epileptic hippocampus. J. Neurosci. 27, 1803-1811. doi: 10.1523/JNEUROSCI.3111-06.2007

Haas, C. A., Dudeck, O., Kirsch, M., Huszka, C., Kann, G., Pollak, S., et al. (2002). Role for reelin in the development of granule cell dispersion in temporal lobe epilepsy. J. Neurosci. 22, 5797-5802.

Häussler, U., Bielefeld, L., Froriep, U. P., Wolfart, J., and Haas, C. A. (2012). Septotemporal position in the hippocampal formation determines epileptic and neurogenic activity in temporal lobe epilepsy. Cereb. Cortex 22, 26-36. doi: 10.1093/cercor/bhr054

Heinrich, C., Nitta, N., Flubacher, A., Müller, M., Fahrner, A., Kirsch, M., et al. (2006). Reelin deficiency and displacement of mature neurons, but not neurogenesis, underlie the formation of granule cell dispersion in the epileptic hippocampus. J. Neurosci. 26, 4701-4713. doi: 10.1523/JNEUROSCI.551605.2006

Herz, J., and Chen, Y. (2006). Reelin, lipoprotein receptors and synaptic plasticity. Nat. Rev. Neurosci. 7, 850-859. doi: 10.1038/nrn2009

Hirotsune, S., Takahara, T., Sasaki, N., Hirose, K., Yoshiki, A., Ohashi, T., et al. (1995). The reeler gene encodes a protein with an EGF-like motif expressed by pioneer neurons. Nat. Genet. 10, 77-83. doi: 10.1038/ng0595-77

Houser, C. R. (1990). Granule cell dispersion in the dentate gyrus of humans with temporal lobe epilepsy. Brain Res. 535, 195-204. doi: 10.1016/00068993(90)91601-C

\section{SUPPLEMENTARY MATERIAL}

The Supplementary Material for this article can be found online at: http://journal.frontiersin.org/article/10.3389/fncel. 2016.00183

Jossin, Y., and Goffinet, A. M. (2007). Reelin signals through phosphatidylinositol 3-kinase and Akt to control cortical development and through mTor to regulate dendritic growth. Mol. Cell. Biol. 27, 7113-7124.

Jossin, Y., Gui, L., and Goffinet, A. M. (2007). Processing of Reelin by embryonic neurons is important for function in tissue but not in dissociated cultured neurons. J. Neurosci. 27, 4243-4252. doi: 10.1523/JNEUROSCI.002307.2007

Jossin, Y., Ignatova, N., Hiesberger, T., Herz, J., Lambert De Rouvroit, C., and Goffinet, A. M. (2004). The central fragment of Reelin, generated by proteolytic processing in vivo, is critical to its function during cortical plate development. J. Neurosci. 24, 514-521. doi: 10.1523/JNEUROSCI.3408-03.2004

Kralic, J. E., Ledergerber, D. A., and Fritschy, J. M. (2005). Disruption of the neurogenic potential of the dentate gyrus in a mouse model of temporal lobe epilepsy with focal seizures. Eur. J. Neurosci. 22, 1916-1927. doi: 10.1111/j.14609568.2005.04386.x

Lambert de Rouvroit, C., de Bergeyck, V., Cortvrindt, C., Bar, I., Eeckhout, Y., and Goffinet, A. M. (1999). Reelin, the extracellular matrix protein deficient in reeler mutant mice, is processed by a metalloproteinase. Exp. Neurol. 156, 214-217. doi: 10.1006/exnr.1998.7007

Lane-Donovan, C., Philips, G. T., Wasser, C. R., Durakoglugil, M. S., Masiulis, I., Upadhaya, A., et al. (2015). Reelin protects against amyloid $\beta$ toxicity in vivo. Sci. Signal. 8, ra67. doi: 10.1126/scisignal.aaa6674

Lee, G. H., and D'Arcangelo, G. (2016). New insights into Reelin-mediated signalling pathways. Front. Cell. Neurosci. 10:122. doi: 10.3389/fncel.2016. 00122

Leemhuis, J., and Bock, H. H. (2011). Reelin modulates cytoskeletal organization by regulating Rho GTPases. Commun. Integr. Biol. 4, 254-257. doi: 10.4161/cib.4.3.14890

Leemhuis, J., Bouché, E., Frotscher, M., Henle, F., Hein, L., Herz, J., et al. (2010) Reelin signals through apolipoprotein $\mathrm{E}$ receptor 2 and $\mathrm{Cdc} 42$ to increase growth cone motility and filopodia formation. J. Neurosci. 30, 14759-14772. doi: 10.1523/JNEUROSCI.4036-10.2010

Marx, M., Haas, C. A., and Häussler, U. (2013). Differential vulnerability of interneurons in the epileptic hippocampus. Front. Cell. Neurosci. 7:167. doi: 10.3389/fncel.2013.00167

Métin, C., Vallee, R. B., Rakic, P., and Bhide, P. G. (2008). Modes and mishaps of neuronal migration in the mammalian brain. J. Neurosci. 28, 11746-11752. doi: 10.1523/JNEUROSCI.3860-08.2008

Müller, M. C., Osswald, M., Tinnes, S., Häussler, U., Jacobi, A., Förster, E., et al. (2009). Exogenous reelin prevents granule cell dispersion in experimental epilepsy. Exp. Neurol. 216, 390-397. doi: 10.1016/j.expneurol.2008.12.029

Murphy, B. L., and Danzer, S. C. (2011). Somatic translocation: a novel mechanism of granule cell dendritic dysmorphogenesis and dispersion. J. Neurosci. 31, 2959-2964. doi: 10.1523/JNEUROSCI.3381-10.2011

Nitta, N., Heinrich, C., Hirai, H., and Suzuki, F. (2008). Granule cell dispersion develops without neurogenesis and does not fully depend on astroglial cell generation in a mouse model of temporal lobe epilepsy. Epilepsia 49, 1711-1722. doi: 10.1111/j.1528-1167.2008.01595.x

Pesold, C., Impagnatiello, F., Pisu, M. G., Uzunov, D. P., Costa, E., Guidotti, A., et al. (1998). Reelin is preferentially expressed in neurons synthesizing gammaaminobutyric acid in cortex and hippocampus of adult rats. Proc. Natl. Acad. Sci. U.S.A. 95, 3221-3226. doi: 10.1073/pnas.95.6.3221

Rakic, P. (1972). Mode of cell migration to the superficial layers of fetal monkey neocortex. J. Comp. Neurol. 145, 61-83. doi: 10.1002/cne.901450105

Ramos-Moreno, T., Galazo, M. J., Porrero, C., Martínez-Cerdeño, V., and Clascá, F. (2006). Extracellular matrix molecules and synaptic plasticity: immunomapping of intracellular and secreted Reelin in the adult rat brain. Eur. J. Neurosci. 23, 401-422. doi: 10.1111/j.1460-9568.2005.04567.x

Riban, V., Bouilleret, V., Pham-Lê, B. T., Fritschy, J. M., Marescaux, C., and Depaulis, A. (2002). Evolution of hippocampal epileptic activity during the 
development of hippocampal sclerosis in a mouse model of temporal lobe epilepsy. Neuroscience 112, 101-111. doi: 10.1016/S0306-4522(02)00064-7

Routbort, M. J., Bausch, S. B., and Mcnamara, J. O. (1999). Seizures, cell death, and mossy fiber sprouting in kainic acid-treated organotypic hippocampal cultures. Neuroscience 94, 755-765. doi: 10.1016/S0306-4522(99)00358-9

Sentürk, A., Pfennig, S., Weiss, A., Burk, K., and Acker-Palmer, A. (2011). Ephrin Bs are essential components of the Reelin pathway to regulate neuronal migration. Nature 472, 356-360. doi: 10.1038/nature09874

Stolt, P. C., and Bock, H. H. (2006). Modulation of lipoprotein receptor functions by intracellular adaptor proteins. Cell. Signal. 18, 1560-1571. doi: 10.1016/j.cellsig.2006.03.008

Stoppini, L., Buchs, P. A., and Muller, D. (1991). A simple method for organotypic cultures of nervous tissue. J. Neurosci. Methods 37, 173-182. doi: 10.1016/01650270(91)90128-M

Tinnes, S., Ringwald, J., and Haas, C. A. (2013). TIMP-1 inhibits the proteolytic processing of Reelin in experimental epilepsy. FASEB J. 27, 2542-2552. doi: 10.1096/fj.12-224899

Tinnes, S., Schäfer, M. K., Flubacher, A., Münzner, G., Frotscher, M., and Haas, C. A. (2011). Epileptiform activity interferes with proteolytic processing of Reelin required for dentate granule cell positioning. FASEB J. 25, 1002-1013. doi: 10.1096/fj.10-168294

Tissir, F., and Goffinet, A. M. (2003). Reelin and brain development. Nat. Rev. Neurosci. 4, 496-505. doi: 10.1038/nrn1113
Yasui, N., Nogi, T., Kitao, T., Nakano, Y., Hattori, M., and Takagi, J. (2007). Structure of a receptor-binding fragment of reelin and mutational analysis reveal a recognition mechanism similar to endocytic receptors. Proc. Natl. Acad. Sci. U.S.A. 104, 9988-9993. doi: 10.1073/pnas.07004 38104

Yasui, N., Nogi, T., and Takagi, J. (2010). Structural basis for specific recognition of reelin by its receptors. Structure 18, 320-331. doi: 10.1016/j.str.2010. 01.010

Zhao, S., Chai, X., Förster, E., and Frotscher, M. (2004). Reelin is a positional signal for the lamination of dentate granule cells. Development 131, 5117-5125. doi: $10.1242 / \mathrm{dev} .01387$

Conflict of Interest Statement: The authors declare that the research was conducted in the absence of any commercial or financial relationships that could be construed as a potential conflict of interest.

Copyright $\odot 2016$ Orcinha, Münzner, Gerlach, Kilias, Follo, Egert and Haas. This is an open-access article distributed under the terms of the Creative Commons Attribution License (CC BY). The use, distribution or reproduction in other forums is permitted, provided the original author(s) or licensor are credited and that the original publication in this journal is cited, in accordance with accepted academic practice. No use, distribution or reproduction is permitted which does not comply with these terms. 